diseases of the nervous system and may also be induced by severe abdominal pain, tympanites, or any form of profound shock. The tonic contraction of the arteries is often very striking and this kind of hypertonus is typically present in some cases of tuberculous meningitis during the irritative stage. Sometimes, even in young children, the radial artery feels like a piece of whipcord, and I have always found the blood pressure extremely low. When as a result of peritonitis or shock, hypertonus is present (the "wiry" pulse), the pressure is also frequently abnormally low, and remedies which produce a relaxation of the vessels lead to a raising of the blood pressure. In such cases there is a general arteriole contraction, due either to direct irritation of the vaso-motor centre (meningitis, cerebral tumour, \&c.), or indirectly produced by some disturbance of the abdominal sympathetic system. There is no unusual obstruction in the capillaries. In some cases of marked arterio-sclerosis in old people, where the lumen of the radial artery was greatly diminished, I have found the blood pressure exceedingly low, but there was no reason to suppose that the capillary area was unduly obstructed. Similarly in old syphilitic vessels with nearly obliterated lumina, the pressure registered was sometimes very low.

In conclusion the following points may be stated : (1) in cases of toxio hypertonus the arterial pressure is, as a rule, considerably raised; and this is mainly brought about by contraction of the capillaries, which, like the arterioles, participate in the area of increased peripheral resistance (2) in non-toxic hypertonus the blood pressure as registered in the radial artery commonly remains unaltered or may be greatly diminished. The obstruction to the flow of blood is then chiefly due to arteriole contraction; the capillary field is not implicated. I am, Sirs, yours faithfully,

Edinburgh, Feb. 16th, 1903. H. OLIPHANT NICHOLSON.

\section{THE VALUE OF CHLORETONE IN SEA-SICKNESS.}

To the Editors of THE LANCET.

SIRS, - When travelling as surgeon of one of the Union Castle steamers I was much struck with the value of "chloretone" (a product of chloroform and acetone prepared by Parke, Davis, and Co.) in some cases of aggravated seasickness. Beginning with a dose of ten grains, I administered five grains at intervals of three hours until the stomach nausea and head congestion were relieved, and the patient sank into a natural and gentle sleep. In every case on waking there was a natural appetite for food and fruit, biscuit, soup, beef-tea, and stimulants were readily retained.

By the continued use of the drug in five-grain doses, at four-hour intervals, the symptoms in the worst affected were controlled for several days of very rough weather and the less affected cases were rendered quite good travellers. The most noticeable clinical feature of its action was the rapid effect produced on the pulse, converting the quick, tense beat of sea-sickness into the fuller and more regular one of health a quarter of an hour after being swallowed. The relief of headache without any heart depression whatever is a very strong point in favour of its use in persons with any organic disease of the heart or kidneys ; and as a pure stimulating hypnotic without any bad after-effects it deserves a foremost place. - I am, Sirs, yours faithfully,

L. WHEELER, M.B., B.Ch. R.U.I.

Junior Conservative Club, London, Feb. 22nd, 1903.

\section{A CASE OF HERNIA INTO THE FOSSA DUODENO-JEJUNALIS.}

To the Editors of THE L A N CET.

SiRs,-Mr. B. G. A. Moynihan in THE LanceT of Feb. 7th, p. 396, has thought it necessary to take notice of my record of a Case of Hernia into the Fossa Duodenojejunalis which appeared in THE LANCET of Jan. 24th, p. 236. This case was carefully dissected and I made drawings of the relations of the parts found. The free margin of the orifice was formed by a thick fibrous mass in which was found the left colic artery; besides this the inferior mesenteric artery, where it came off the aorta, could be said to form the lower cornu of the opening. The inferior mesenteric vein was distant to the left from this margin about half an inch. It did not, as Mr. Mopnihan presumes, occupy the "neck" of the sac, but ran almost vertically at the above-mentioned distance. For this reason is it not probable that the case was properly named? Mr. Moynihan says that the condition of the fossa to be properly appreciated must be studied in the foetus or young child. I have it on the authority of a most careful observer and competent embryologist (possibly the most competent in the country), whose observations will probably soon appear, that out of a series of 47 foetuses in only one was there the slightest suspicion of a fossa of any kind in the neighbourhood of the duodenum, so that the nine fossæ so exactly described by Mr. Moynihan are probably formed later in life.

Aberdeen, Feb. 16th, 1903. I am, Sirs, yours faithfully,

\section{ANEURYSM OF THE ASCENDING AORTA. To the Editors of THE LANCET.}

SiRs,-I have read Dr. A. C. Jordan's paper in The LanCET of Feb. 21st, p. 515, on aneurysm of the ascending aorta in a small boy with great interest. One cannot help regretting, however, that the chest was not examined during life with the $x$ rays. True, there were no physical signs calling special attention to the chest, but I venture to think that had the chest been so examined much light might have been thrown on the case. The aneurysm, judging from Figs. 1 and 2, was quite large enough to have been so detected. The only element of doubt in the diagnosis would have been between an aneurysm and enlarged bronchial glands, the latter condition being, of course, much more likely in a child six years of age, but the continuity of the shadow with that of the heart and aorta, and more especially the pulsation of the sac, would, I think, have left no doubt about the diagnosis. I venture to think that the day will come when a patient will be examined with the $x$-ray screen as a matter of routine in the same way as he is now examined with the stethoscope, and I think the sooner that day comes the better. I, for my part, can only say that I have found $x$-ray examination of the chest in my out-patient room and in private practice of very great value. I am, Sirs, yours faithfully,

Harley-street, W., Feb. 21st, $1903 . \quad$ HUGH WALSHAM.

\section{THE CULTIVATION OF ANAEROBIC BACTERIA.}

To the Editors of THE LANCET.

SiRs,-Mr. H. S. Fremlin draws attention in a note on p. 518 of THE LANCET of Feb. 21st to a method of cultivating anaerobic bacteria in plate, of which a detailed account is promised in the forthcoming report of the medical officer of the Local Government Board. Will you allow me to draw Mr. Fremlin's attention to the fact that a method based on identical principles and manipulations has already been described by myself in the report of the medical officer of the Local Government Board for 1897-98 on p. 219.

I am, Sirs, yours faithfully,

St. Bartholomew's Hospital, Feb. 21st, 1903. E. KLEIN.

\section{APPENDICITIS IN ITS ACUTEST FORMS : A CORRECTION.}

To the Eatitors of THE LANCET.

SrRs,-Will you kindly grant me space to correct an error and one omission in my paper upon appendicitis? The error appears in connexion with the numbers and the mortality of the cases of typhlitis and peritonitis occurring in St. Bartholomew's Hospital in the years 1882 to 1884 . In all 79 cases were registered with a mortality of 23 -not 41 , as stated on p. 503 of THE LANCET of Feb. 21st.

The omission is the want of any reference to a note in the British Medical Journal of April 5th, 1892, p. 54, to which I am indebted for valuable information and through which my attention was first drawn to the work of Battey regarding the occurrence of pelvic peritonitis in the male sex.

Cannes, Feb. 23rd, 1903. I am, Sir, yours faithfully, J. A. MacDougall.

\section{A QUESTION IN INEBRIETY.}

To the Editors of THE LAXCET.

Sirs,-In The Lancet of Feb. 21st, p. 552, Mr. C. E. Macnamara states his opinion that the inebriate is possessed of a strong will and asks the opinions of your readers. If 